\title{
How does social media interactivity affect brand loyalty?
}

\author{
Travis K. Huang \\ Ling Tung University \\ travisk.huang@gmail.com
}

\author{
Chun-Yung Liao \\ Ling Tung University
}

ccbbaac50208@gmail.com

\author{
Yi-Ting Wang \\ Ling Tung University \\ yw7@,umail.iu.edu
}

\author{
Kuan-Yu Lin \\ Ling Tung University \\ ntustmislab@gmail.com
}

\begin{abstract}
As social media has become a prominent platform for networking, many organizations have begun to establish more than one brand community, as a set of supplements to their branded websites. Once most online brand interactions take place on social networking sites rather than branded sites, such customer-oriented interactions will become much more complicated and unpredictable. It is a real challenge for organizations to build successful customer-brand relationships through social networking sites. Hence, organizations that wish to enhance brand loyalty by running brand communities face the challenge of effectively conducting social customer relationship management (CRM) tactics. As social media users are susceptible to highly interactive features, understanding the nature of social media interactivity in brand communities is the key to building successful social CRM. The aim of the study is to investigate not only the effect of social media interactivity on community benefits, but also the effect of community benefits on brand loyalty. In addition to measuring the direct effects of social influence and media richness on brand loyalty, the study assessed the indirect effect of responsiveness on brand loyalty by means of community benefits, including knowledge gains and sense of membership. The results, based on data collected from 229 social media users who are followers of Super Basketball League (SBL) teams' Facebook pages, indicated that media richness had a strong, positive, and direct effect on brand loyalty, and that responsiveness had direct effects on their knowledge gains and their sense of membership, which in turn affected brand loyalty indirectly.
\end{abstract}

\section{Introduction}

Unquestionably, the most popular Internet activity these days is social networking. In the U.S., 73 percent of Internet users had a social networking profile in October 2015, up from 48 percent in 2010. The number of social media users is expected to exceed 200 million in 2019, up from 180 million in 2015 [1]. According to the results of a survey regarding social media marketing tactics in 2013, 73 percent of U.S. marketers had established branded pages on social networks [2]. Although branded websites are still the most popular sites for online brand interactions, we can foresee the growth of brand communities on social networking sites in the future. Once most online brand interactions take place on social networking sites rather than branded sites, such customer-oriented interactions will become much more complicated and unpredictable. It is a real challenge for organizations to build successful customer-brand relationships through social networking sites.

As social media has become a prominent platform for networking, many organizations have begun to establish more than one brand community, as a set of supplements to their branded websites. In fact, these brand communities on social networking sites are spaces for people of common interests to discuss and share experiences by posting their user-generated content (UGC)[5][6], thereby providing opportunities for instant engagement. In this trend toward social CRM, the customers find that the distinction becomes blurred between being consumers on a website and being producers of content on a social networking site. In addition to being consumers who are browsing the website, the customers become content providers for the website. To understand the influence of UGC in their own brand communities on social networking sites, organizations should make greater efforts to monitor multiple brand communities. Hence, firms that wish to enhance brand loyalty by running brand communities face the challenge of effectively conducting CRM tactics, and especially social CRM tactics.

Many researchers have defined the perceived interactivity between users in terms of their psychological states during interactions with specific online media or websites [8][9][10]. These researchers have found that the consumers' perceived interactivity has a positive effect on their attitudes toward the website [11] and on their emotional responses toward the brand community [12]. Social media interaction, which is measured by the quantities of various social media used, has been shown to have a positive effect on relationship quality [12]. In considering the salience of social media, this study adopts and enriches the concept of perceived interactivity. It proposed a 
construct to examine social media interactivity by adding two dimensions, namely social influence and media richness. As social media users are susceptible to highly interactive features, understanding the nature of social media interactivity in brand communities seems to be the key to building successful social CRM. Accordingly, the study aimed to investigate and clarify the effects of social media interactivity on community benefits.

The Super Basketball League (SBL), founded in 2003, is the top-tier semi-professional men's basketball league in Taiwan. There are currently seven teams in the SBL, including the Bank of Taiwan, Dacin Tigers, Fubon Braves, Kinmen Kaoliang Liquor, Pauian Archiland, Taiwan Beer and Yulon Luxgen Dinos. Each team has its own official site and offers its fans various types of brand communities. Members of these communities on sites such as Facebook, Pinterest, YouTube and Twitter contribute personal information related to their interests and participate in specialized groups or forums. The target community of this study is the SBL's brand communities on social networking sites. This study investigated the effects of social media interactivity on brand communities on social networking sites in the context of the SBL in Taiwan. An investigation was conducted over two years.

The subjects in the study were members of SBL's brand communities. In addition to gaining greater understanding on how to increase the members' brand loyalty by launching brand communities on social networking sites, the study objectively assessed the factors that improve community benefits. The causal linkages between social media interactivity and community benefits were evaluated. Hence, this study intended to answer the following questions: How does social media interactivity in brand communities on social networking sites improve the members' community benefits and enhance brand loyalty? What is the relationship between the members' community benefits and their loyalty toward the brand? What is the relationship between the members' social media interactivity and community benefits?

\section{Literature review}

\subsection{Social CRM}

CRM systems have been widely used in helping organizations to contact customers and to generate comprehensive analyses of their customers by collecting, storing and analyzing customer data. However, to achieve success in this effort, CRM systems need to operate faster and to support the process of customer knowledge creation [13][14][15]. As we know, tacit knowledge is unwritten and hidden knowledge, which is stored in individuals' brains, is based on their emotions, experiences, insights, intuitions, observations and internalized thoughts. Thus, tacit types of knowledge such as genres and skills are difficult or even impossible to codify by writing them down completely [30]. Actually, tacit knowledge can be elicited and transferred from one person to another through their interactions by joining in common activities. Nowadays, this potential may be expanded greatly through sharing concepts, stories, skills and genres in groups and communities with the use of multi-media platforms and social media. Therefore, if organizations want to promote the growth of their customers' knowledge (and especially their experienced knowledge), they should make greater efforts to enable the customers to conduct socialization more abundantly by means of social media and collaborative CRM systems.

Social CRM systems are the most up-to-date, collaborative CRM systems. These improved systems focus on establishing and managing strong relationships between organizations and users through creating positive experiences concerning the organization's brands, products and services on social networking sites (SNS). The objectives of social CRM are to extract the greatest value from customers over the lifetime of the relationship [3] and to turn the organization's social media connections into loyal customers. Once organizations embrace social CRM, they have a chance to facilitate dialogue and collaborative experiences that their customers will appreciate [3]. Therefore, it is a widespread practice for organizations to establish their own branded social network groups or pages and to create brand communities on social media networking sites [5][6].

\subsection{Brand community on SNS}

Social networking sites (SNS), which are also called "social networking services," are platforms for users to develop personal social networks or relations by creating public profiles and maintaining lists of friends. Most SNS platforms are websites that provide users with mobile connectivity, blogging and multimedia sharing. On social networking sites such as Facebook, Twitter and Myspace, people can easily keep up-to-date with their friends' goings-on. Thus, users with common interests are not only able to interact with others by sharing ideas, pictures, posts, activities, events and interests, but they are also able to form communities, which are the most conspicuous types of virtual networks.

A brand community is a virtual community based on a structured set of social relationships among the consumers of a brand [17]. With the trend toward SNS, organizations increasingly tend to establish their own 
brand communities for customers to contribute their experiences, opinions and experiences. The customers achieve this by annotating, transforming and recirculating various types of social media content. By doing so, the customers are forming meaningful connections with a specific brand. For example, Facebook fan pages have proven highly useful in strengthening the relationships between organizations and their customers [4].

Indeed, brand communities on SNS have become the new mode of socialization platforms for conducting social CRM by fulfilling specific requirements such as exchanging information, sharing experiences and generating knowledge [5][6]. In terms of pinpointing the importance of brand interactivity, some researchers have demonstrated that following a brand's Facebook updates can lead to positive brand evaluations [18]. Individuals in these virtual communities are encouraged to interact with one another over a shared passion. The community members are allowed to interact in pursuit of their mutual interests by means of specific social media. Especially in a brand community on SNS, all of the members are (potentially) content producers rather than just consumers on a brand website. What the users see on SNS influences their impression of the brand, their loyalty and their intention to purchase directly. Thus, both the quality and the quantity of UGC (user-generated content) play important roles in shaping the management of customer relationships within the brand communities on SNS.

\subsection{Community benefits}

Virtual communities provide members with social interaction and information exchange online. This interaction emphasizes the element of social psychology between community members. The benefits social media users gain from joining a brand community are actually "customer-focal relationship benefits," which are rewards, or functional and social benefits such as time saving, convenience, companionship or improved decision making [19]. However, as the goals of the study were focused on the relationship between users and brand communities rather than on the user-brand relationship, the benefits to be investigated are termed "community benefits."

The first dimension in the construct of community benefits is "knowledge gains," which pertains to the users' perceived gains in knowledge, including both tacit and explicit forms of knowledge. Brand community members have a strong interest in the brand. As they usually have extensive brand knowledge and related experience, they support each other in solving problems and generating new ideas or solutions. Therefore, brand communities can be a valuable source of knowledge [20]. Furthermore, social media have been proven to affect their users' knowledge gains. For instance, the duration of daily Twitter use has been found to positively predict hard news knowledge, but daily Twitter use showed a negative influence on soft news knowledge [21]. Overall, the use of SNS leads to greater online knowledge-sharing behavior by the users [22]. The daily use of Facebook has also been shown to be a strong predictor of incidental-knowledge gains from SNS.

The "sense of membership" is the second dimension in the construct of community benefits. As all members can potentially attain and receive support in their communities, another benefit of virtual communities is the feeling of membership or belonging that they can give to their members [7]. In the proposed study, the sense of membership is defined as a member's feeling of identification with or attachment to a brand community on SNS.

To create customer relationships, the customers' perceived value has to be increased by providing relational benefits, including social, confidence and special treatment benefits [25]. As social benefits refer to the emotional part of the relationship, this type of companionship is similar to the "sense of membership" dimension in the study. Confidence benefits pertain to perceptions of comfort in knowing what to expect in the service encounter, whereas special treatment benefits are price breaks or personal services for customers. Neither confidence benefits nor special treatments benefits are easily observed or measured in the context of brand communities on SNS, but these kinds of benefits can be interpreted as part of the dimension of "knowledge gains," which this study will measure as units of knowledge. In fact, special treatment benefits and confidence benefits are associated with knowledge and information gains. Once the users gain needed knowledge, they may improve their decision making, save their time, earn special treatment and grow familiar with what to expect in the brand community. Thus, the construct of community benefits is developed based on relationship benefits, and the measurement of this construct was further modified to fit the context of the study.

The importance of loyalty has been clearly shown in many studies, and the evidence shows that customer loyalty has a strong, positive influence on sales, customer retention, share of wallet, brand word-ofmouth and firm profitability [4][26]. In this regard, it is critical for organizations to identify the antecedents of customer loyalty for the sake of improved CRM, and especially in relation to social CRM. In the study, 
brand loyalty is defined as the member's favorable attitude toward the brand.

As the formation of brand communities has been proven to increase consumer loyalty [5][6], community benefits play a significant role [25][27]. In addition, as Baird and Parasnis (2011)[3] explained, engaging with a company via social media often leads to a feeling of connectedness. Such emotion is similar to a sense of membership (SOM). In some studies, the sense of membership was measured under other similar terms such as "social identity" or "user identification." For instance, members with greater levels of affective social identity (or identification with their friendship group in the virtual community) have been found to have greater feelings of attachment and belongingness [28]. User identification with the brand community is also an important determinant of a user's willingness to become active in a brand community [20]. Specifically, social media users with higher levels of engagement usually demonstrate a stronger sense of membership. Such sense of membership helps to encourage the development of relationships, not only between consumers and brands, but also between consumers and brand communities. Based on the foregoing reasoning, the study proposes the following hypothesis.

Hypothesis 1: Community benefits are positively related to brand loyalty.

As the study proposes the construct of community benefits, which includes the dimensions of knowledge gains and sense of membership, hypothesis 1 is expanded as follows.

Hypothesis 1a: Knowledge gains are positively related to brand loyalty.
Hypothesis 1b: Sense of membership is positively related to brand loyalty.

\subsection{Social media interactivity}

Virtual communities on SNS provide their members with a popular environment for social activities in which people can interact by exchanging resources such as information, ideas or advice about their common interests. Social media have shifted the power of communication from traditional consumers to social media users, who may not have an actual purchase experience or a clear interest in a brand. Therefore, not only for the sake of advisement, but also for the sake of conducting social CRM, organizations should strive to make better use of virtual communities on SNS to communicate with members of the public, whether they are already community members or not. According to interactivity theory [29], the quality of communication is the most critical factor for interactivity. If organizations have better communication with their members on SNS, then a higher level of interactivity will be perceived in the virtual community.

Over the past decade, perceived interactivity has been defined as the users' psychological state during their interactions with a website [30]. However, the concept of perceived interactivity was first proposed by Newhagen, Corders and Levy (1995) [31]. In their study on the content analysis of e-mail messages, interactivity was defined based on the two dimensions of efficacy (including the sense of system efficacy) and perceived interactivity. Subsequently, Wu (1999)[32] used these two dimensions to investigate perceived interactivity by describing them as the as "internalbased efficacy" and "externally based system efficacy" dimensions.

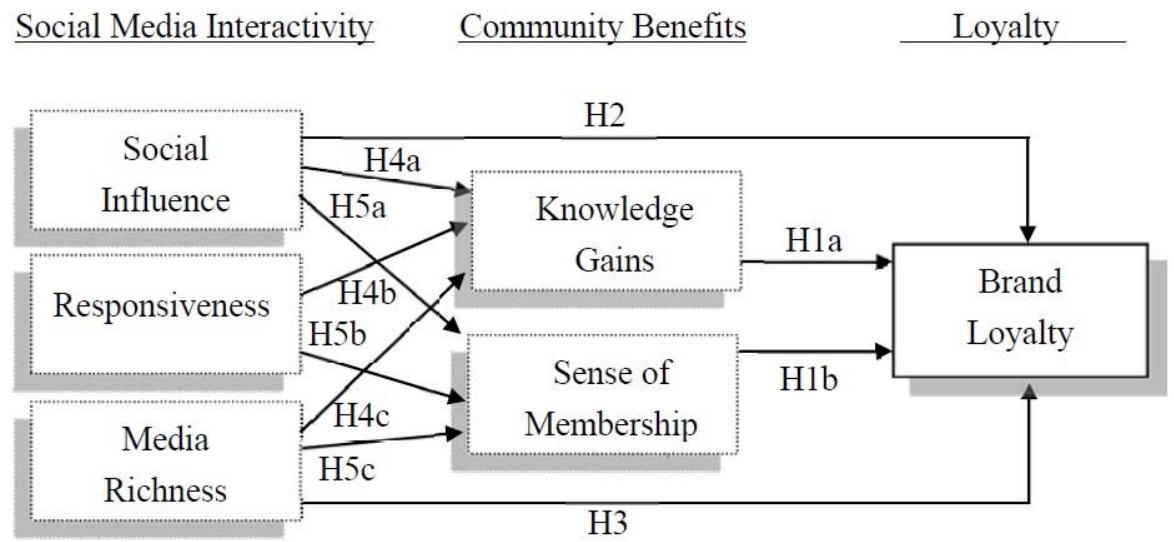

Figure 1. Conceptual Model. 
The first term refers to "perceived control," and the second term represents "perceived responsiveness." McMillan and Hwang (2002)[8] and Liu (2003)[33] identified a third dimension of "communication" to measure the degree of two-way interaction. Many researchers have chosen these three dimensions as their core constructs for measuring perceived website interactivity [8][9][10][11][34].

With the emergence of social media, the evidence has been increasing that our understandings of perceived interactivity on SNS need to be updated. For example, the level of interaction in virtual communities was proven to influence consumers' commitment to the community [35]. Wang, $\mathrm{Yu}$ and Wei (2012)[36] demonstrated that peer communication and socialization by means of social media influences not only the community members' product attitudes directly, but also their purchase intentions indirectly. In the study, perceived interactivity was investigated in the context of virtual communities on SNS. It is believed that the level of such perceived interactivity in social media use is definitely different from what is experienced on websites. As Tremayne (2005) [37] suggested, it is necessary to manipulate interactivity by varying the nature of the dimensions involved according to a specific online medium or website. Thus, perceived interactivity was adopted in the study without considering communication and control constructs, and defined as the users' perception of interactivity in the brand community on SNS. This is because the difference in communication and control is quite limited in the context of virtual communities on SNS. To explicitly draw the distinction between socialmedia-influenced interactivity and website interactivity, we propose the concept of "social media interactivity," which includes not only responsiveness, but also two new dimensions that consider the salience of social media, namely social influence and media richness. Both of these dimensions are critical features in which social media users are highly interested when they interact with virtual communities on SNS.

Social influence refers to a community's influential power, which is measured by the perceived volumes of clicks, likes and retweets that members receive in their virtual communities.

By means of such feedback, the members are able to learn what content has influence and what content does not. Both personal influence on the community and the community's influence on its members are important factors in attracting and retaining social media users. Hence, the users' experience of these kinds of influence helps to increase the perceived social media interactivity of virtual communities. In addition, the literature on this subject, however, has commonly treated social influence as similar to colleague opinion toward the use of a specific medium [38], rather than as a measure of a community's influential power. Thus, the study would like to measure the users' perceived social influence in specific communities on SNS, and to investigate the effect on brand loyalty. Hypothesis 2 is proposed as follows.

\section{Hypothesis 2: Social influence is positively related to brand loyalty.}

The other dimension to be measured is "media richness," which represents a member's perception toward the variety of media presented in a virtual community. According to media richness theory [39], various media differ in their degrees of richness, with "richness" defined as the capacity for enabling users to convey information, and thus to facilitate their acquisition of shared meaning and understanding. Social media users have tended to have higher perceptions of interactivity if some of the social cues that are available in face-to-face communication become available through new information technologies [11]. In fact, an SNS can provide people with social cues in a variety of formats and media. As all types of media and links can be shared on SNS, the users are able to access and transfer the content they pick. When the content is presented with a greater variety of media, the users are able to acquire knowledge and information according to their preferences.

It is more absorbing for people to share and acquire each other's experiences through media with higher richness. By offering such increased richness, brand communities have a better chance of keeping the users browsing or sharing experiences. Consequently, the users will perceive higher levels of brand loyalty. Hence, hypothesis 3 is proposed as follows.

\section{Hypothesis 3: Media richness is positively related to brand loyalty.}

As the website has become the most highly used interactive marketing tool [40], there is a tendency for both marketers and website designers to try their best to enhance the interactive capabilities of their websites. Many studies have shown the influence of website interactivity on the users' thoughts, emotions and behavior [41]. In the context of the study, the effects of social media interactivity on the members' thoughts, emotions and behavior were investigated in terms of community benefits.

The quality of content posted to a brand community is critical to the users' perceived interactivity. For example, according to interactivity theory [29], 
message quality has a positive effect on the users' perceptions of interactivity and of system effectiveness. People have higher interactivity perceptions when they receive high-quality, personalized messages [9]. That is, when high-quality, personalized and particularly relevant UGC is provided in brand communities on SNS, the members tend to perceive greater social media interactivity. In fact, UGC is viewed as a unit of knowledge in the study. Once the quality of knowledge becomes the key to increasing social media interactivity, the UGC is likely to become more beneficial and appealing to social media users. Based on this reasoning, the following hypothesis is proposed.

Hypothesis 4: Social media interactivity is positively related to knowledge gains.

As social media interactivity includes three dimensions, namely social influence, responsiveness, and media richness, hypothesis 4 is expanded as follows.

Hypothesis 4a: Social influence is positively related to knowledge gains.

Hypothesis 4b: Responsiveness is positively related to knowledge gains.

Hypothesis 4c: Media richness is positively related to knowledge gains.

Furthermore, the relationship between community usage and the sense of membership has been clearly identified in the literature [42]. In some studies, the sense of membership was measured under other similar terms such as "social identity" or "user identification." Social identification has been seen as motivating members to participate in online brand community interactions [43]. Social bonding, which actually indicates the sense of membership, has been proven to influence consumer-to-consumer interactions in virtual communities [35]. In addition, social media interaction (which is measured by the quantity of social media used by respondents) has shown a positive effect on users' emotions toward a brand community [12]. Therefore, social media interactivity is not only positively related to knowledge gains, but also related to the sense of membership. This observation leads to following hypothesis.

Hypothesis 5: Social media interactivity is positively related to sense of membership.

The construct of social media interactivity is proposed by the study, and includes social influence, responsiveness, and media richness dimensions. Hence, hypothesis 5 is expanded as follows.

Hypothesis 5a: Social influence is positively related to sense of membership.

Hypothesis 5b: Responsiveness is positively related to sense of membership.

Hypothesis 5c: Media richness is positively related to sense of membership.

\section{Research method}

\subsection{Subjects}

Two hundred forty-one current followers of SBL Facebook pages were invited to fill out our questionnaire online. These subjects were social media users with experience in posting their thoughts, feelings or stories to specific brand communities, such as the followers of an SBL team's Facebook page. In addition, the subjects were familiar with discussing or responding to others by texting, sharing photos and posting links. Specifically, the subjects were members of SBL-related communities.

\subsection{Procedure}

To investigate the effects of social media interactivity in terms of sharing experiences between community members, questionnaires were administered to approximately 240 social media users who participated in one of the communities associated with the seven teams of the SBL. Participants were informed that they were involved in a research project, but were kept blind to the research hypotheses.

The questionnaire assessed the participants' perceptions of their social media interactivity, community benefits and brand loyalty while using social media to interact with other members on a specific brand's Facebook page. The research model shown in Figure 1 was tested in reference to the survey data collected.

\subsection{Measurement}

Brand loyalty. The seven items of brand loyalty were adapted from the scales developed by Plank and Newell [49], with modifications to measure the degree of the member's loyalty intentions toward the brand. 
Table 1. Correlations between Variables

\begin{tabular}{|c|c|c|c|c|c|c|}
\hline & 1 & 2 & 3 & 4 & 5 & 6 \\
\hline 1.Social influence & 1 & & & & & \\
\hline 2.Responsiveness & $.845^{* *}$ & 1 & & & & \\
\hline 3. Media richness & $.808 * *$ & $.858 * *$ & 1 & & & \\
\hline 4.Knowledge gains & $.671^{* *}$ & $.646^{* *}$ & $.528 * *$ & 1 & & \\
\hline 5.Sense of membership & $.649 * *$ & $.722 * *$ & $.636 * *$ & $.769 * *$ & 1 & \\
\hline 6.Loyalty & $.604^{* * *}$ & $.673^{* *}$ & $.671 * *$ & $.484^{* * *}$ & $.709 * *$ & 1 \\
\hline
\end{tabular}

Social media interactivity. Three dimensions were included in the construct of social media interactivity: responsiveness, social influence and media richness. It used McMillan and Hwang's [44] scale for measuring responsiveness (six items). Many researchers have applied this scale to examine website interactivity. The scale shows a high level of reliability and generalizability. Cronbach's $\alpha$ for this six-item measure was .775. In addition, social influence is defined as the community's influential power, measured by each member's perceived volume of clicks, likes or retweets in the virtual communities, whereas media richness represents the member's perception of the variety of the media presented in the virtual community. Both measurements were developed in the study by exploring and identifying appropriate items [45][46][47]. Cronbach's $\alpha$ for social influence (six items) was .915, whereas Cronbach's $\alpha$ for media richness (four items) was .857 .

Community benefits. As the study proposed the construct of community benefits, two dimensions were identified: knowledge gains and sense of membership. We developed three items to measure the levels of members' perceived knowledge gains (including tacit knowledge and explicit knowledge) from their engagement in brand communities by exploring and identifying appropriate items [48]. In addition, the sense of membership was measured by referencing related scales [43]. Cronbach's $\alpha$ for knowledge gains (three items) was .933, whereas Cronbach's $\alpha$ for sense of membership (six items) was .943.

\section{Results}

Of the 241 followers of SBL teams' Facebook pages, 229 completed the online questionnaire, giving a response rate of $95 \%$. The correlations between the variables were tested using Pearson's correlation coefficient. As shown in Table 1, all of the variables were positively interrelated.
In addition, knowledge gains was highly correlated with sense of membership ( $r>.6$ ), and social influence was also highly related to both responsiveness and media richness.

As we expected, both social media interactivity and community benefits showed a high level of composite reliability and internal consistency. However, correlation does not imply causation. The causal relationship between the variables was further examined using structural equation modeling.

Using the 229 records, the proposed model was assessed with maximum likelihood estimation using AMOS. All of the calculations were based on the covariance matrix of the variables. Five common model-fit measures were used to assess the model's overall goodness of fit, the ratio of $\chi 2$ to degrees of freedom (CMIN/DF), goodness-of-fit (GFI), adjusted goodness-of-fit index (AGFI), comparative fit index (CFI), and root mean square error of approximation (RMSEA).

The results indicated that the proposed model $(\mathrm{CMIN} / \mathrm{DF}=1.031 ; \mathrm{GFI}=.998, \mathrm{AGFI}=.968, \mathrm{CFI}=.996$, RMSEA $=.012, p=.310$ ) had a good fit, because all of the criteria were better than the recommended values $(\mathrm{CMIN} / \mathrm{DF}<3$; GFI $>.90$, AGFI $>.80, \mathrm{CFI}>.90$, RMSEA $<.80$ ). Thus, we used the model to examine our hypotheses.

As shown in Figure 2, the standardized path coefficients running from sense of membership to brand loyalty were statistically significant; thus Hypothesis 1b was supported. Although the standardized path coefficients running from knowledge gains to brand loyalty were significant, the effect was negative rather than positive, thereby disconfirming Hypothesis 1a.

As the standardized path coefficients running from social influence to brand loyalty were not significant, Hypothesis 2 was not supported. In addition, the standardized path coefficients running from media richness to brand loyalty were significant. Hence, Hypothesis 3 was confirmed. 
$\underline{\text { Social Media Interactivity } \quad \text { Community Benefits } \quad \text { Loyalty }}$

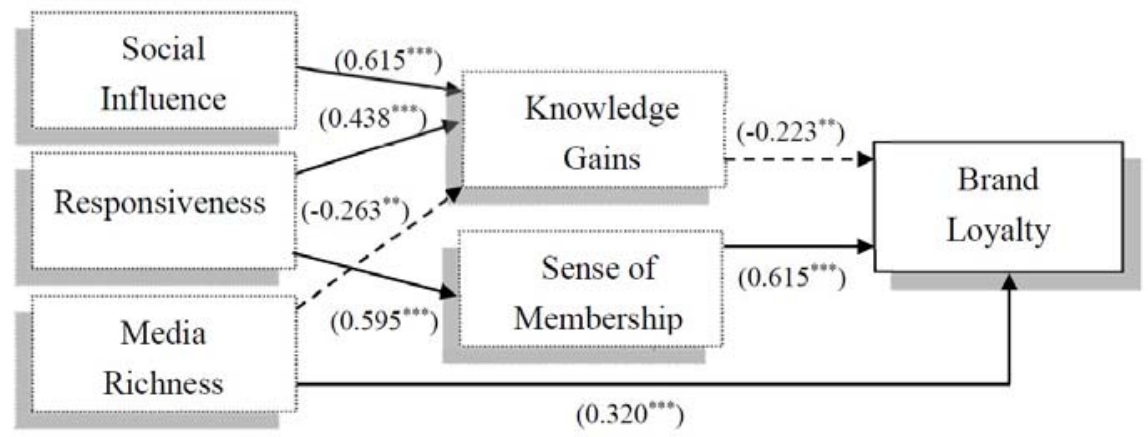

Figure 2. Standardized Path Coefficients of the Proposed Model (Note. ${ }^{*} \mathrm{p}<.05 .{ }^{*} \mathrm{p}<.01 .{ }^{* * *} \mathrm{p}<.001$.)

All of the paths to knowledge gains were significant, but only the standardized path coefficients from media richness were negative, while the others were positive. Thus, Hypothesis $4 \mathrm{a}$ and $4 \mathrm{~b}$ were supported, and Hypothesis 4c was not. Furthermore, the paths running from social influence and media richness to sense of membership were not significant, disconfirming Hypotheses 5a and 5c. The path running from responsiveness to sense of membership was statistically significant, thereby supporting Hypotheses $5 b$.

The $\mathrm{R}^{2}$ value indicated that $60 \%$ of the variance in brand loyalty was explained by these variables. Responsiveness had indirect effects rather than direct effects on brand loyalty, due to its direct effects on knowledge gain and sense of membership, whereas social influence affected only knowledge gains directly. Hence, both responsiveness and social influence affected brand loyalty indirectly, whereas media richness had both direct and indirect effects on brand loyalty by means of knowledge gains.

\section{Conclusion}

The emergence of social media has changed the consumer's role in experience sharing. Consumers have moved from being passive listeners or watchers to becoming active participants. This development is important for organizations, as it indicates that they need to not only design memorable experiences, but also to promote such experiences by means of social media. In attempting to do so, organizations may find that the brand communities on social networking sites are helpful for expressing every type of experience. By promoting multi-media to share experience, users' loyalty will be enhanced.
During this study, the effects of social media interactivity, including social influence, responsiveness and media richness, on brand loyalty were examined by measuring users' perceived social media interactivity on SBL teams' Facebook pages. This was accompanied by empirical examination of the effects of community benefits, including knowledge gains and sense of membership, on brand loyalty.

Overall, media richness and sense of membership were found to have positive effects on brand loyalty. Surprisingly, knowledge gains were found to have a negative effect on brand loyalty. Social influence was found to have significant effects on knowledge gains, which affected brand loyalty negatively. However, the effect of media richness was negative, whereas social influence and responsiveness were positive. A practical implication is that it is worthless for SBL teams to promote social media users' knowledge by providing higher-richness media on Facebook pages if they desire to retain brand loyalty.

In addition, responsiveness was found to have a positive effect on sense of membership, which affected brand loyalty positively. Based on this finding, we recommend that SBL teams increase social media users' loyalty by promoting their sense of membership through quick and accurate responses on their Facebook pages. An important practical implication of our findings is that brand communities may improve their social media users' loyalty directly by making use of higher-richness media on Facebook pages.

\section{Acknowledgments}

This research is partially supported by Ministry of Science Technology in Taiwan under project number MOST-105-2410-H-275-002. 


\section{References}

[1] Experian, "Leading social media websites in the United States in October 2015, based on share of visits", 2015, Retrieved from http://www.statista.com/statistics/265773/marketshare-of-the-most-popular-social-media-websites-inthe-us/

[2] Statista, "Most popular types of online brand interactions according to global internet users as of 3rd quarter 2014", 2015, Retrieved from http://www.statista.com/statistics/376078/onlinebrand-interactions/

[3] C. H. Baird, and G. Parasnis, "From social media to social customer relationship management", Strategy \& Leadership, 39(5), 2011, pp. 30-37.

[4] B. Jahn, and W. Kunz, "How to transform consumers into fans of your brand", Journal of Service Management, 23(3), 2012, pp. 344-361.

[5] M. Laroche, M. R. Habibi, and M. O. Richard, "To be or not to be in social media: How brand loyalty is affected by social media?", International Journal of Information Management, 33(1), 2013, pp. 76-82.

[6] M. R. Habibi, M. Laroche, and M. O. Richard, "The roles of brand community and community engagement in building brand trust on social media", Computers in Human Behavior, 37, 2014, pp. 152-161.

[7] C. Luo, X. R. Luo, Y. Xu, M. Warkentin, and C. L. Sia, "Examining the moderating role of sense of membership in online review evaluations", Information \& Management, 52(3), 2015, pp. 305-316.

[8] S. J. McMillan, and J. S. Hwang, "Measures of perceived interactivity: An exploration of the role of direction of communication, user control, and time in shaping perceptions of interactivity", Journal of Advertising, 2002, pp. 29-42.

[9] J. H. Song, and G. M. Zinkhan, "Determinants of perceived web site interactivity", Journal of Marketing, 72(2), 2008, pp. 99-113.

[10] J. Schamari, and T. Schaefers, "Leaving the home turf: How brands can use webcare on consumergenerated platforms to increase positive consumer engagement", Journal of Interactive Marketing, 30, 2015, pp. 20-33.

[11] N. Cui, T. Wang, and S. Xu, "The influence of social presence on consumers' perceptions of the interactivity of web sites", Journal of Interactive Advertising, 11(1), 2010, pp. 36-49.

[12] S. Hudson, M. S. Roth, T. J. Madden, and R. Hudson, "The effects of social media on emotions, brand relationship quality, and word of mouth: An empirical study of music festival attendees", Tourism Management, 47, 2015, pp. 68-76.
[13] A. Barua, C. H. Kriebel, and T. Mukhopadhyay, "Information technologies and business value: An analytic and empirical investigation", Information systems research, 6(1), 1995, pp. 3-23.

[14] A. Rai, S. S. Lang, and R. B. Welker, "Assessing the validity of IS success models: An empirical test and theoretical analysis", Information systems research, 13(1), 2002, pp. 50-69.

[15] M. Khalifa, A. Y. Yu, and K. N. Shen,"Knowledge management systems success: a contingency perspective", Journal of Knowledge Management, 12(1), 2008, pp. 119-132.

[16] S. D. Cook, and J. S. Brown, "Bridging epistemologies: The generative dance between organizational knowledge and organizational knowing", Organization science, 10(4), 1999, pp. 381-400.

[17] A. M. Muniz Jr, and T. C. O'guinn, "Brand community", Journal of consumer research, 27(4), 2001, pp. 412-432.

[18] C. J. Beukeboom, P. Kerkhof, and M. de Vries, "Does a virtual like cause actual liking? How following a brand's Facebook updates enhances brand evaluations and purchase intention", Journal of Interactive Marketing, 32, 2015, pp. 26-36.

[19] R. W. Palmatier, R. P. Dant, D. Grewal, and K. R. Evans, "Factors influencing the effectiveness of relationship marketing: a meta-analysis", Journal of marketing, 70(4), 2006, pp. 136-153.

[20] J. Füller, K. Matzler, and M. Hoppe, "Brand community members as a source of innovation", Journal of Product Innovation Management, 25(6), 2008, pp. 608-619.

[21] E. J. Lee, and S. Y. Oh, "Seek and you shall find? How need for orientation moderates knowledge gain from Twitter use", Journal of Communication, 63(4), 2013, pp. 745-765.

[22] W. W. Ma, and A. Chan, "Knowledge sharing and social media: Altruism, perceived online attachment motivation, and perceived online relationship commitment", Computers in Human Behavior, 39, 2014, pp. 51-58.

[23] J. Barney, M. Wright, and D. J. Ketchen, "The resource-based view of the firm: Ten years after 1991", Journal of management, 27(6), 2001, pp. 625-641.

[24] B. Schivinski, and D. Dabrowski, "The effect of social media communication on consumer perceptions of brands", Journal of Marketing Communications, (ahead-of-print), 2014, pp. 1-26.

[25] K. P. Gwinner, D. D. Gremler, and M. J. Bitner, "Relational benefits in services industries: the customer's perspective", Journal of the academy of marketing science, 26(2), 1998, pp. 101-114.

[26] G. Odekerken-Schröder, K. De Wulf, and P. Schumacher, "Strengthening outcomes of retailerconsumer relationships: The dual impact of 
relationship marketing tactics and consumer personality", Journal of business research, 56(3), 2003, pp. 177-190.

[27] T. S. Dagger, and T. K. O'Brien, "Does experience matter? Differences in relationship benefits, satisfaction, trust, commitment and loyalty for novice and experienced service users", European Journal of Marketing, 44(9/10), 2010, pp. 1528-1552.

[28] H. T. Tsai, and R. P. Bagozzi, "Contribution behavior in virtual communities: Cognitive, emotional, and social influences", MIS Quarterly, 38(1), 2014, pp. 143-163.

[29] S. Rafaeli, "Interactivity: From new media to communication", Sage annual review of communication research: Advancing communication science, 16(CA), 1988, pp. 110-134.

[30] G. Wu, "Conceptualizing and measuring the perceived interactivity of websites", Journal of Current Issues \& Research in Advertising, 28(1), 2006, pp. 87104.

[31] J. E. Newhagen, J. W. Cordes, and M. R. Levy, "Nightly@ nbc. com: Audience scope and the perception of interactivity in viewer mail on the Internet", Journal of communication, 45(3), 1995, pp. 164-175.

[32] G. Wu, "Perceived interactivity and attitude toward web sites", In Proceedings of the conferenceAmerican Academy of Advertising, 1999. American Academy of Advertising, pp. 254-262.

[33] Y. Liu, "Developing a scale to measure the interactivity of websites", Journal of advertising research, 43(02), 2003, pp. 207-216.

[34] P. B. Lowry, N. C. Romano, J. L. Jenkins, and R. W. Guthrie, "The CMC interactivity model: How interactivity enhances communication quality and process satisfaction in lean-media groups", Journal of Management Information Systems, 26(1), 2009, pp. 155-196.

[35] K. W. Chan, and S. Y. Li, "Understanding consumer-to-consumer interactions in virtual communities: The salience of reciprocity", Journal of Business Research, 63(9), 2010, pp. 1033-1040.

[36] X. Wang, C. Yu, and Y. Wei, "Social media peer communication and impacts on purchase intentions: A consumer socialization framework", Journal of Interactive Marketing, 26(4), 2012, pp. 198-208.

[37] Tremayne, M., "Lessons learned from experiments with interactivity on the Web", Journal of Interactive Advertising, 5(2), 2005, pp. 40-46.

[38] S. M. Wang, and J. Chuan-Chuan Lin, "The effect of social influence on bloggers' usage intention", Online Information Review, 35(1), 2011, pp. 50-65.

[39] R. L. Daft, R. H. Lengel, and L. K. Trevino, "Message equivocality, media selection and manager performance: Implications for information systems", MIS Quarterly, 11, 1987, pp. 355-366.

[40] P. Barwise, and J. U. Farley, "The state of interactive marketing in seven countries: interactive marketing comes of age", Journal of Interactive Marketing, 19(3), 2005, pp. 67-80.

[41] G. Van Noort, H. A. Voorveld, and E. A. van Reijmersdal, "Interactivity in brand web sites: cognitive, affective, and behavioral responses explained by consumers' online flow experience", Journal of Interactive Marketing, 26(4), 2012, pp. 223234.

[42] H. Lin, W. Fan, and L. Wallace, "The effects of social and technical factors on user satisfaction, sense of belonging and knowledge community usage", International Journal of e-Collaboration, 9(3), 2013, pp. 13-30.

[43] D. Lee, H. S. Kim, and J. K. Kim, "The impact of online brand community type on consumer's community engagement behaviors: Consumer-created vs. marketer-created online brand community in online social-networking web sites", Cyberpsychology, Behavior, and Social Networking, 14(1-2), 2011, pp. 59-63.

[44] S. J. McMillan, and J. S. Hwang, "Measures of perceived interactivity: An exploration of the role of direction of communication, user control, and time in shaping perceptions of interactivity", Journal of Advertising, 2002, pp. 29-42.

[45] J. R. Carlson, and R. W. Zmud, "Channel expansion theory and the experiential nature of media richness perceptions", Academy of management journal, 42(2), 1999, pp. 153-170.

[46] J. Schmitz, and J. Fulk, "Organizational colleagues, media richness, and electronic mail a test of the social influence model of technology use", Communication research, 18(4), 1991, pp. 487-523.

[47] J. R. Carlson, and R. W. Zmud, "Channel expansion theory and the experiential nature of media richness perceptions", Academy of management journal, 42(2), 1999, pp. 153-170.

[48] W. H. DeLone, and E. R. McLean, "Information systems success: The quest for the dependent variable", Information systems research, 3(1), 1992, pp. 60-95.

[49] R. E. Plank, and S. J. Newell, "The effect of social conflict on relationship loyalty in business markets", Industrial Marketing Management, 36(1), 2007, pp. 5967. 